\title{
Guerra en los libros. La competencia colonial del siglo XVIII entre Gran Bretaña y Francia en los libros del Museo Etnográfico de Buenos Aires (1690-1800) ${ }^{1}$
}

\author{
Rogelio C. Paredes \\ Facultad de Filosofía y Letras-UBA
}

\begin{abstract}
Resumen
Tras la prolongada decadencia del predominio español en Europa y la más reciente crisis del colonialismo holandés, Gran Bretaña y Francia se disputaron el dominio en los mares y los territorios de ultramar a lo largo de la primera mitad del siglo XVIII. El conflicto, que se resolvería a favor de los británicos con su victoria sobre los franceses en la Guerra de los Siete Años (1756-1763), dejó sus huellas en un prolongado duelo editorial con que ambos países trataron de conocer, traducir y difundir la literatura de viajes del otro, con vistas a beneficiase con sus descubrimientos y anticiparse a sus planes de conquista y adquisición.

El propósito del artículo consiste en describir algunos aspectos de esta doble confrontación -militar y editorial- sobre la base de los libros de viaje existentes en la biblioteca del Museo Etnográfico de Buenos Aires. En su acervo bibliográfico se destaca una significativa cantidad de ediciones en inglés y francés. Estos documentos revelan el interés recíproco de estas potencias por sus avances geográficos, coloniales y científicos a todo lo largo del siglo XVIII.

Sobre la base de los libros existentes en el Museo Etnográfico, este trabajo no sólo procura documentar en el plano intelectual, científico y editorial la competencia diplomática y militar entre los colonialismos británico y francés, sino también indagar la importancia de la difusión bibliográfica como instrumento de propaganda de sus objetivos coloniales y de incorporación de los intereses del público lector a la empresa de expansión comercial y territorial en ultramar.
\end{abstract}

Palabras clave: Francia - Gran Bretaña - Colonialismo - Literatura de Viajes - Siglo XVIII

\section{Abstract}

After the long Spanish domination over Europe, and the decadence of Holland's colonialism, Great

1 Una versión previa de este artículo fue presentado en las VII Jornadas Nacionales de Historia Moderna y Contemporánea. Diálogos entre el pasado y el presente frente al Bicentenario, 18, 19 y 20 de octubre de 2010, Universidad Nacional de Cuyo, Facultad de Filosofía y Letras. Las notas y citas de este artículo procuran transcribir completos los títulos de los libros citados, en su ortografía original.

PAREDES, Rogelio, "Guerra en los libros. La competencia colonial del siglo XVIII entre Gran Bretaña y Francia en los libros del Museo Etnográfico de Buenos Aires (1690-1800)" en Avances del Cesor, Año VIII, № 8, 2011, pp. 129-154. 
Britain and France disputed his domination over the seas in the first half of Eighteenth century. The conflict was solved with the brutish victory over France during the Seven Years' War (1756-1763) and marked the books' edition in both countries for the knowledge, translation and dissemination of voyages'.narratives, in order to achieve new discoveries and anticipate next conquest and possessions. This article proposes make a description of theses conflicts from the military and publishing events, from the books of Museo Etnográfico de Buenos Aires' Library. This library have a lot of English and French texts on voyages and explorations of colonial territories. These books show the important and mutual interest between Great Britain and France for the geographical, colonial and scientific achievement in the Eighteenth century.

About these books, this article shows the intellectual, scientific and publishing competition further diplomatic and military rivalry between British and French colonialism. Besides, it analyses the importance of voyages'. Narratives for the advertising of colonial enterprise and its commercial and territorial aims to the public in order achieve his support.

Key words: France - Great Britain - Colonialism - Voyages' Narratives - Eighteenth century

Aunque manteniendo el anonimato, el autor de la Histoire des Navigations aux Terres Australes (París, 1756) asumía plenamente, aunque entre líneas, que su tarea de historiador y de escritor dedicado a entretener al público con el tema de su obra, involucraba también inevitablemente, las responsabilidades del hombre de Estado.

(Las narraciones sobre el mar austral se encontraban hasta ahora) sumidas en una inmensa multitud de relatos, en lengua latina, española, inglesa y holandesa, en las que nadie se había atrevido a buscarlas; en una cantidad de expediciones muy áridas, muy aburridas, relativas a centenares de objetos distintos, por lo cual sería casi imposible procurar una lectura interesante... Fue necesario rendirse, ante todo, a la consideración de que los conocimientos aquí reunidos pudiesen un día servir de algo a nuestra nación, para adquirir allí las más grandes y mejores posesiones sobre este mundo desconocido, cuando se haya tomado el partido de recorrer por completo sus rutas en lo que se refiere a la marina, de poner sus sentidos y sus recursos principales a organizar flotas numerosas de guerra y de comercio, como es evidente que debe hacerse con ellos por su propio interés, y lo mismo por necesidad del estado actual de Europa, en una cuestión en que una potencia vecina afecta visiblemente la monarquía universal del mar, sin consideración ni miramientos para ninguna otra nación. He aquí lo que ha dado nacimiento a esta obra que fue hecha en poco tiempo, que el autor nunca soñó hacer. ${ }^{2}$

2 Histoire des Navigations aux terres australes contenant ce que l'on sait des navigations des mœurs et des productions des Contrées découvertes jusqu' a ces jours... Paris. Chez Durand, rue de Foin au Griffon 1756. Avec Approbation et Privilege du Roy, 2 tomos, pp. 5-6. Todas las citas de originales franceses e ingleses realizadas en este artículo son traducción del autor. 
Servir a la patria y agradar al lector: el autor de este texto, Charles de Brosses (1709-1777) llegó varias veces a desempeñarse en lugares prominentes de la magistratura, pero nunca dejó acallar su vocación por las letras, la filosofía y las ciencias naturales. Su Histoire des Navigations marcó un hito en la geografía mundial, cuando bautizó con la denominación de Australasia y Polinesia las extensas regiones oceánicas que debían haber coincidido con la Terra Austral Incógnita que buscaban holandeses e ingleses desde un siglo atrás. La fecha de la publicación de la obra, 1756, el año de inicio de la Guerra de los Siete Años, y de la apertura de las hostilidades contra los británicos - con sus perspectivas de una ampliación de las posibilidades de expansión colonial francesa- muestra hasta qué punto las armas, las letras y la ciencias colaboraban íntimamente en la Francia ilustrada de Luis XV.

Siete años después, cuando la Paz de París de 1763 sellaba la victoria de los enemigos británicos, los franceses tuvieron ocasión de experimentar la frustración de sus proyectos $\mathrm{y}$, al mismo tiempo, la crisis de su literatura de viajes que trataba de ser su soporte discursivo. Las consecuencias del conflicto dejó sus huellas visibles en el prolongado duelo editorial con que ambos países trataron de conocer, traducir y difundir la literatura de viajes del otro, con vistas a beneficiase con sus descubrimientos y anticiparse a sus planes de adquisición. La más vigorosa literatura de viajes inglesa iba imponiéndose en los mercados europeos como un instrumento de mayor aptitud para el conocimiento y el dominio del mundo ultramarino, en un género bastante diverso del que habían cultivado los súbditos de la cristianísima monarquía al otro lado del Canal de la Mancha. Los exitosos viajes del inglés George Anson (1740-1744) y del francés Louis Antoine Bougainville (1766-1769) realizados durante el desarrollo de los conflictos militares anglo-franceses del siglo XVIII, representaron bien ese contraste en la forma de producir, escribir y hacer circular la información obtenida en los viajes por ambas potencias antagónicas y permiten, quizá, señalar algunos de sus contrastes.

Una de las más notables manifestaciones de este duelo pueden reconocerse en el rico fondo bibliográfico de la sección de Viajeros de la Biblioteca Augusto Raúl Cortazar del Museo Etnográfico de Buenos Aires, que contiene numerosos relatos de viajes de los siglos XVII, XVIII, XIX e inicios del XX. Este conjunto de lecturas siguen constituyendo un material de invalorable interés para analizar las aristas culturales y editoriales de diversas etapas de la vida social, económica y política de la Europa Moderna y de sus dependencias americanas. Con sus 584 volúmenes, este fondo bibliográfico proporciona una perspectiva singular para esta parte del mundo sobre la literatura de viajes y sobre sus extensas implicancias en todos los aspectos de la historia moderna mundial, considerándola como un resultado dinámico de las interacciones entre las metrópolis y sus colonias. Sus libros de viaje constituyen una fuente estudiada de la historia europea y ultramarina, que permite situar los discursos y las prácticas de los exploradores, conquistadores y colonizadores en 
ultramar como elemento constitutivo -y decisivo- de su propia situación en Europa y el mundo, según las cambiantes coyunturas del contexto moderno/colonial. ${ }^{3}$

Sobre la base de estas numerosas ediciones de época francesas y británicas, este artículo se propone analizar diversos aspectos relacionados con los relatos de viaje (editores, traducciones, dedicatorias y públicos) como un componente relevante de los intereses antagónicos de ambas potencias en busca de movilizar la opinión de los lectores a favor de sus proyectos y, al mismo tiempo, de alentar en ellos su participación en la empresa colonial, centrándose particularmente en los relatos de viajes franceses del siglo XVIII, numéricamente más representativos que los británicos. Se procura demostrar, entonces, de qué modo y en qué medida la materialidad y el contenido de los textos, volcados incluso a la lengua de los adversarios, no sólo refleja la intensa competencia entre Francia y Gran Bretaña por la posesión de los territorios de ultramar, sino que presenta, claros indicios de la diferencia que tenía la práctica social de los viajes a ambos lados del Canal de la Mancha en términos de objetivos, de actores sociales involucrados, de expectativas económicas y políticas y de formas de circulación social de la información. Esta doble confrontación, a la vez militar y editorial, documenta el interés recíproco de ambos países por los avances geográficos, coloniales y científicos de sus rivales desde fines del siglo XVII y hasta mediados del siglo XVIII, en el plano intelectual y literario, y la competencia diplomática y militar entre los dos colonialismos británico y francés; y procura avanzar en un intento de definir la importancia de la difusión bibliográfica como instrumento de propaganda de sus objetivos coloniales y de incorporación de los intereses del público lector a la empresa de expansión colonial. La empresa editorial puede comprenderse así como parte de una interacción más amplia en la cual el crecimiento económico, las aspiraciones sociales, el conflicto militar y la diplomacia ocupan cada una su papel, objeto de análisis de este artículo. Su desarrollo intenta documentar las diversas etapas de la competencia entre ingleses y franceses según las cambiantes condiciones de estos diversos factores.

\section{Inglaterra toma la ofensiva: científicos de Londres y bucaneros del Caribe (1660-1715)}

Con la declinación de la potencia marítima y comercial holandesa, a mediados de la década de 1670, el escenario de las posesiones y aspiraciones europeas en ultramar quedó enteramente abierto a la competencia de sus grandes rivales de aquélla: Inglaterra y Francia. Después de 1672, la República de las Provincias Unidas había enfrentado el doble desafío de resistir una invasión de sus territorios por las tropas de Luis XIV y de sostener un

3 Concepto tomado de la obra de MIGNOLO, Walter, Local Histories/Global Designs. Coloniality, Subaltern Knowledges and Border Thinking, Princeton University Press, Princeton, 2000, para aludir al carácter dialéctico del proceso en la conformación de la modernidad europea. 
extendido frente de guerra naval contra los ingleses en los mares de Europa, de América y Asia. Las paces sucesivas con Inglaterra (1674) y con Francia (1678), si bien preservaron la independencia política y la integridad territorial holandesa, afectaron su status de potencia naval. ${ }^{4} \mathrm{El}$ lugar que dejaba vacante al frente del colonialismo europeo se dirimiría entre finales del siglo XVII y mediados del XVIII entre sus enemigos de 1672.

En esa disputa por la herencia naval y colonial holandesa, sin embargo, resulta claro que Inglaterra obtendría una ventaja inicial sobre su rival francesa. Por la evolución de la diplomacia europea del momento ${ }^{5}$ el estallido de la Revolución Gloriosa en diciembre de 1688, Guillermo III de Orange, estatúder de la república holandesa, se convirtió a su vez en soberano de Inglaterra hasta 1702, y ambas rivales se unieron no sólo para derrotar los planes de expansión continental de Francia, sino que los ingleses recibieron de sus aliados, además, un notable caudal de conocimientos, técnicas y recursos que supieron emplear muy bien en la preparación de su futura expansión colonial. Además de los nuevos procedimientos agrícolas, su organización bancaria, su sistema de asistencia pública y parte de los capitales de su empresa colonial, los ingleses incorporaron de los holandeses conocimientos marítimos y geográficos para sus empresarios y navegantes.

La colaboración angloholandesa en diplomacia, guerra, comercio y navegación que auspiciaba el estatúder y rey Guillermo III de Orange dejó, herencias significativas. El acceso de los miembros de la Royal Society de Londres a las narraciones de viaje holandesa -que ya circulaban por Europa en versiones originales menos accesibles del holandés, o en latín- permitió la más amplia divulgación de esos textos en idioma inglés. Es el caso de la difundida recopilación de viajes de Tancred Robinson, Un relato de diversos viajes y descubrimientos recientes, ${ }^{6}$ Robinson, médico de la corte y miembro de la Real Sociedad, la publicó por primera vez en 1694 y volvió a editarla en 1711, incluyendo en ella no sólo los viajes de los ingleses John Narbrough y John Wood, con sus respectivas exploraciones del Atlántico Sur y del Mar del Norte -el segundo en busca del paso al Océano Pacífico por el Noreste- sino también las expediciones holandesas de Abel Tasman en el Pacífico Sur y de Fredrick Marteen en Groenlandia, todas ellas, como declara el título, concretadas en las décadas de 1670 y 1680 . El editor inglés complementaba así, con ingenio, un esquema muy completo de trayectos muy diversos: el viaje de Tasman podía ensamblarse con el de Narborough al Estrecho de Magallanes -a través del cual llegó a Chile y el Pacífico-mientras

4 ISRAEL, Jonathan, The Dutch Republic. Its Rise, Greatness and Fall, 1477-1806, Clarendon Press, Oxford, 1995, capítulos 29-32.

5 Por el tratado de Westminster (febrero de 1674), Inglaterra y Holanda concluyeron la guerra, y se iniciaron las gestiones diplomáticas que concluyeron con la unión matrimonial entre María Estuardo, sobrina de Carlos II y Guillermo de Orange (noviembre de 1676) ambos convertidos, después de 1688 , en soberanos de Inglaterra.

6 An Account of several late Voyages and Discoveries to the South and the North, Welford, London, 1694. 
que las exploraciones -comprobadamente inútiles- de Wood por los helados mares del Polo Norte podían añadirse al viaje de Marteen a Groenlandia. La versión original holandesa de los viajes de la recopilación de Robinson es la de Peter van der Aa, Naukeurige Verdameling der Gedenkwaardigste Zee en Land Reysen (Ámsterdam, 1706-1708) que incorporaba, a su vez, traducciones de algunos viajes ingleses al Caribe y al Brasil, de gran interés para la Compañía Holandesa de Indias Occidentales, que mantenía todavía posesiones en Curazao, Guyana y Antillas. En la Biblioteca de Museo Etnográfico puede verse un ejemplar de la compilación de Tancred Robinson en su edición de 1694.

Las mencionadas ventajas de Inglaterra en conocimientos, recursos y adquisiciones territoriales no procedían tan sólo de la acción combinada de los círculos académicos y de los miembros de su elite mercantil, sino también de la tumultuosa vida de parte de sus sectores marginales, que habían emigrado para establecerse en las Antillas y, desde sus bases, asolaban los puertos y flotas españolas y publicaban en la metrópoli los relatos de sus aventuras. La variopinta población de europeos -no sólo ingleses- dedicados a la cría de ganado, la explotación forestal, el cultivo de caña de azúcar y el merodeo contra el tráfico español de metales y manufacturas surgía también de las tensiones sociales y culturales que atravesaban sus metrópolis. En esta experiencia particular de la colonización del Atlántico, la marginación socio-política y cultural de estos hombres, denominados genéricamente bucaneros, configuró una sociedad cuyas características originales hicieron posible el fermento de ideas, actitudes y comportamientos que pondrían en crisis el orden político y económico que los había arrastrado hasta allí. ${ }^{7}$ Hacia finales del siglo XVII, esa población sólo marginalmente dedicada al asalto y saqueo de navíos, comenzó a provocar la crisis del poder español en la región. En las tres últimas décadas del siglo XVII, la ofensiva de los bucaneros caribeños alcanzó un punto culminante. Los ataques sobre las instalaciones españolas en Antillas y Tierra Firme adquirieron grandes dimensiones, a la cabeza de las cuales estuvo en ese momento el célebre Henry Morgan, con base en Port Royal, Jamaica.

Como verdadera "sociedad de fronteras" consolidada en el Caribe, los bucaneros demostraron, con sus operaciones de fines del siglo XVII, y sobre todo de comienzos del XVIII, la eficacia militar, económica, cultural y literaria de su turbulenta organización lanzada a la conquista de la riqueza arrebatada a la monarquía española. En el centro de esta experiencia inicialmente pirática y finalmente literaria y científica, se encontraba un hombre que articularía en torno de sí acciones e intereses muy diversos: William Dampier (1652-1715) quien adquirió un rápido renombre por la extensión, variedad y diversidad de los viajes realizados por América, el Pacífico, Asia Oriental y el Indico, y en cuya descripción se hizo notar por sus cualidades como narrador, geógrafo, naturalista, meteorólogo y etnógrafo. En 1697 apareció su primer libro, al que debió parte de su renombre: A New

7 LINEBAUGH, Peter y REDIKER, Marcus, La hidra de la revolución. Marineros, esclavos y campesinos en la historia oculta del Atlántico, Crítica, Barcelona, 2005. 
Voyage round the World, y al que dos años más tarde agregó una segunda parte titulada Voyages and Descriptions y un Discourse of the Winds. Sus viajes posteriores (1699-1701) fueron reunidos en un nueva obra publicada en 1703 bajo el título A Voyage to New Holland, dedicaba de manera exclusiva a sus exploraciones por Australia y Nueva Guinea, a la cual completó, en 1709, con una segunda parte. Luego de desempeñarse ocasionalmente como ayudante y capataz en plantaciones de Centroamérica y Antillas, Dampier se alistó en navíos ingleses dedicados a actividades de contrabando y piratería en el Golfo de México y en proximidades del Istmo de Panamá. Pasó luego al Pacífico y a las costas de Perú y de Chile, donde entre 1678 y 1681 operó a las órdenes del capitán William Sharp (o Sharpe), atacando y saqueando embarcaciones y puertos españoles. A partir de 1683, una serie de singulares aventuras lo alejaron del escenario americano y lo llevaron desde las costas de Virginia hasta los mares de Asia, desde donde, casi sin proponérselo, terminó por realizar, en varias etapas, la circunnavegación del planeta. Su segundo viaje, previsto para realizar una navegación interoceánica entre el Atlántico y el Pacífico por el Estrecho de Magallanes, se vio modificado y lo condujo al Océano Indico a través del Cabo de Buena Esperanza. La carrera de Dampier continuó con dos nuevas travesías como corsario, en la segunda de las cuales (1708-1711) le tocó desempeñarse como piloto del célebre capitán Woodes Rogers. ${ }^{8}$ La empresa de Rogers, parte de las operaciones de la Guerra de la Sucesión Española (1702-1713), fue singularmente exitosa, y su concepción y puesta en marcha se atribuye también a Dampier. ${ }^{9}$

Dampier, hombre notable de un grupo de bucaneros y marinos, se rodeó de hombres que, a su vez, adquirieron celebridad con la publicación de sus propias aventuras. El primero de todos ellos fue su compañero Basil Ringrose, quien publicó primero sus hazañas y noticias sobre América y el Caribe..$^{10}$ Otros de sus camaradas descollaron en las décadas posteriores como narradores. El año 1699, el mismo en que

Dampier publicó sus Voyages and Descriptions, y su Discourse of the Winds, como apéndices de sus viajes por el Atlántico, el Indico y el Pacífico, el capitán William Hacke editaba una breve colección de narrativas bajo el descriptivo título de A collection of original Voyages containing: Capt. Cowley's Voyage round the Globe; Capt. Sharp's Journey over the Isthmus of Darien and Expedition into the South Sea, written by himself; Capt. Woods' Voyage throu' the Streights of Magellan; Mr. Roberts'Adventures among the Corsaires of

8 SILVERBERG, Robert, The Longest Voyage. Circumnavigations in the Age of the Discovery, Ohio University Press, Athens, 1997, p. 496 y s.; WOODARD, Collin: La República de los Piratas. La verdadera historia de los piratas del Caribe, Crítica, Barcelona, 2008, pp. 51-52, 72-75 y 80-83.

9 Ibídem, pp. 72-75.

10 RINGROSE, Basil, "Journal”, EXQUEMELINM Alexander, History of the Buccaneers, V. II, Londres, 1685. 
the Levant; his Account of their Way of living, Description off the Archipelago's Islands, Turkey and Siria, London, Imprenta James Knapton, 1699.

Ambrose Cowley y Bartholomew Sharp también pertenecían al círculo de relaciones de Dampier: el primero había sido piloto del capitán John Cooke, a cuyas órdenes sirvió aquél durante la primera parte de su viaje alrededor del mundo, y el segundo, su capitán en varias empresas realizadas sobre las costas de América destinadas a controlar el tráfico español sobre el Pacífico atacándolo desde Panamá, que después de un exitoso comienzo, se interrumpieron por querellas entre Sharp y Coxon, y que en agosto de 1681 concluyeron en un regreso a Barbados por la ruta del Cabo de Hornos, donde arribó con sus hombres el 28 de junio de 1682. ${ }^{11}$ Por su parte, Lionel Waffer, aventurero, cirujano y náufrago inglés en las aguas del Caribe, que había acompañado a Dampier en incursiones sobre el istmo de Panamá, publicó ese nismo año A New Voyage and Description of the Isthmus of América, giving an Account of the Autor's Abode there,... the Indian Inhabitants, their features, complexion... their manners, customs, employments, mariages, feasts, hunting, computation languages, etc. dedicada de manera mucho más especifica al Istmo de Panamá y a las poblaciones indígenas del Darién. ${ }^{12}$

\section{Francia replica: Froger, Frezier y los viajes de la Compañía de Indias Orientales (1689-1715)}

Como se ha visto, la configuración de las alianzas político-militares europeas bajo el reinado de Luis XIV operó decisivamente en el proceso de construcción y desarrollo del imperialismo ultramarino de sus protagonistas. El estallido de la guerra franco holandesa y el triunfo de la Revolución Gloriosa en Inglaterra consolidaron, como se dijo, una alianza anglo-holandesa opuesta al expansionismo del monarca francés. ${ }^{13}$ La guerra de la Liga de Augsburgo (1689-1697) sirvió para promover el estallido simultáneo de un conflicto

11 STEPHEN, Leslie y LEE, Sidney (editores), The Dictionary of National Biography. Founded en 1882 by George Smith. From the Earliest Times to 1900, Published since 1917 by the Oxford University Press, 1968, V. X VII, pp. 1357-1358.

12 HACKE, William, Voyages containing: Capt. Cowley's Voyage round the Globe; Capt. Sharp's Journey over the Isthmus of Darien and Expedition into the South Sea, written by himself; Capt. Woods' Voyage throu' the Streights of Magellan; Mr. Roberts' Adventures among the Corsaires of the Levant; his Account of their Way of living, Description of the Archipelago's Islands, Turkey and Siria,, Imprenta James Knapton, Londres, 1699; WAFER, William, A New Voyage and Description of the Isthmus of America giving an Account of the Author's Abode there... the Indians inhabitants, the features, complexion... their manners customs, employments, mariages, feats, hunting, computation, languages, Londres, 1699.

13 STOYE, Jens, El despliegue de Europa, 1648-1688, Siglo XXI Editores, Madrid, 1974, capítulo $11-12$. 
territorial -los esfuerzos de los enemigos de Francia por resistir su avance hacia el Rhin-y otro dinástico - la lucha contra los intentos de Luis XIV por restaurar en el trono inglés a su aliado católico, Jacobo I Estuardo, en contra del holandés Guillermo III de Holanda, soberano de Inglaterra.

La Francia de Luis XIV no contaba con el recurso a una alianza tan decisiva para alentar su expansión colonial, ni tampoco con un número tan significativo de súbditos aventureros que aportaran información valiosa como su competidora insular. Los franceses sabían, en efecto, que desde mediados de la década de 1680 circulaban entre los lectores ingleses y holandeses unas obritas singulares cuya eficacia superaba la de sus publicistas y hombres de Estado. En 1678, en Amsterdam, había aparecido en holandés la primera edición de la Historia de los Bucaneros de América, del emigrado hugonote francés y médico Alexander Exquemelin, cuyas traducciones inglesa (1684) y francesa (1686) tuvieron un efecto decisivo en el interés y en la forma de conocer y comprender las oportunidades que proporcionaba América a los que se atrevían a desafiar el monopolio español. Pero la Guerra de Devolución (1667-1668) y la política de "fronteras naturales" con anexiones en los Países Bajos y el Franco Condado habían provocado el enfrentamiento abierto con la monarquía española, la única potencia que, por su secular enemistad con Holanda y por su inmenso imperio colonial podría haber contrapesado la carencias francesas en ese campo. ${ }^{14}$

Esta situación permite comprender porqué Rene Ausguste Constantin de Renneville, hugonote francés exiliado en los Países Bajos, publicó en Amsterdam, en 1710, un Recueil des Voyages, qui ont servi a l'établissement et au progrès de la Compagnie des Indes Orientales formée dans las Provinces Unies des Pais-Bas, en dos tomos, dedicados al contralor general y secretario de Guerra de Luis XIV, Michel de Chamillart, funcionario impopular por su pobre desempeño en la Guerra de la Sucesión Española. Su propósito había sido, escribe el autor:

...prometerme algún éxito en el designio que he tenido, de animar a nuestra nación a servirse de los viajes que han servido al establecimiento y al progreso de la Compañía de Indias Orientales formada en las Provincias Unidas de los Países Bajos, para procurarse riquezas que pueden ir hasta el infinito... que los particulares pueden llevar al exceso sin hacer sufrir a los pueblos, y que el público podrá poner con seguridad a todo uso legítimo a cambio de su servicio, proporcionando placer a los pueblos, inclusive a los más alejados, y sin el temor de algún enfadoso retorno. Tales bienes, Monseñor, que nunca dan remordimientos a quienes los procuran, ni disgusto a quienes se sirven de ellos, ni dolores a los que los disfrutan, ni quejas a la menor cualidad del honesto hombre cristiano, serán de la naturaleza de la cual Vuestra delicadeza aspira para secundar las intenciones del más sabio y más poderoso de los Monarcas. ${ }^{15}$

14 DUCHHARDT, Heinz, La época del Absolutismo, Alianza, Madrid, 1992, capítulos 2 y 5. 15 CONSTANTIN DE RENNEVILLE, Remé, A, Recueil des Voyages, qui ont servi a l'établissement et au progrès de la Compagnie des Indes Orientales formée dans las Provinces Unies des Pais-Bas, 
La exposición de Renneville no llega tan lejos: cubre las dos décadas iniciales de la expansión de las Provincias Unidas tras la derrota de la Armada Invencible y se cierra a comienzos de 1600. La grandeza de Francia, buscada con esta divulgación de los informes de un súbdito hereje en tierras de una Iglesia Reformada -informes que se parecen mucho a la tarea de un espía- deberá proceder de la sabia imitación de los recursos holandeses para enriquecerse en ultramar. Pero los británicos disponían al respecto de fuentes de información y medios de difusión que los franceses no lograron imitar, pese a que, como se advierte, se esforzaron seriamente en hacerlo.

Tratando de tomar la iniciativa, durante, el transcurso mismo de la guerra de la Liga de Augsburgo (1689-1697) la monarquía francesa intentó -y fracasó en su intento-ir por detrás de los bucaneros en su guerra contra España, prueba de la rápida y extendida circulación de las noticias sobre sus empresas. El 3 de junio de 1695, una armada compuesta por seis navíos de guerra franceses, partió de El Havre al mando del señor de Gennes, con más de setecientos hombres y 120 piezas de artillería, con el objetivo de explorar las principales bases europeas para la navegación del Atlántico y cruzar el Estrecho de Magallanes, en busca de las ricas americanas costas sobre el Pacífico de Perú y Centroamérica. El cronista de la expedición, que dice llamarse Froger y haber participado de la empresa con apenas diecinueve años, incorporó a su obra más de treinta mapas y grabados sobre peces, plantas, animales, instituciones y costumbres de los pueblos de África y de América que llegó a visitar. ${ }^{16}$ Los ingleses lo tradujeron a su lengua y lo incorporaron al elenco de relatos de viajes ultramarinos hechos por bucaneros que florecieron en torno a ese mismo año. ${ }^{17}$

Los expedicionarios franceses regresaron a su país el 21 de abril de 1697 sin haber hostigado el tráfico español sobre el Pacífico, al que nunca lograron llegar. Froger expone al lector que el proyecto de su capitán habría sido directamente inspirado por bucaneros ingleses deseosos de resarcirse de pérdidas suscitadas en aventuras anteriores

Hacia el año 1686, algunos Filibusteros de la Isla de Santo Domingo... después de haber batido muchos años las costas de Caracas, Nueva España y Cuba, sin haber logrado ninguna fortuna, se resolvieron a pasar a las del Mar del Sur, que sabían que eran más ricas y menos fortificadas... El pasaje del Estrecho de Magallanes les

Seconde Edition, Au depense de Etienne Roger, Marchand Librairie, Amsterdam, 1710, 2 tomos, pp. 6-7.

16 FROGER, [François], Relation d'un Voyage de la Mer du Sud, Détroit de Magellan, Brésil, Cayenne, et les îles Antilles, ou l'on voit les Observations que l'Auteur a faites sur la Religion, Mœurs, et Coutumes des Peuples qu'y habitent. Enfin, les divers Animaux s'y trouvent du même que des Fruits et les Plantes qu'y croisent. Par le Mr. Froger. Enrichi des Figures dessinées sur lieux et gravées fort proprement. A Ámsterdam. Chez Honoré et Chatelet, 1715.

17 FROGER, [François], A Relation of a Voyage made into the years 1695, 1696, 1697 on the Coast of Africa, Streights of Magellan, Brasil, Cayenna and the Antilles, by a Squadron of French Men of War, under the Command of M. De Gennes, London, 1698. 
pareció más seguro, entraron en número de cuatrocientos veinte hombres en la Mar del Sur... se retiraron a distancia hasta algunas islas donde dedicaron su tiempo a la caza y a la pesca...

Luego de haber llevado esta vida funesta por espacio de siete años, resolvieron algunos regresar a la patria, volviendo a pasar al Mar del Norte, se reunieron a tal efecto en la Isla Fernando (Juan Fernández?) donde repartieron su botín... Ante la resolución de regresar, veintitrés de ellos a quienes el azar del juego había hecho perder lo que durante todo ese tiempo habían ganado, se quedaron en esta Isla con una piragua... resueltos a perecer o a volver a ganar al menos lo que tenían... Uno de ellos, nombrado Marcety, se dirigió a Monsieur de Gennes, del que sabía que era muy emprendedor. Monsieur de Gennes escuchó su proyecto y fue a París a volver a presentar las consecuencias a la Corte. ${ }^{18}$

El Museo Etnográfico conserva un raro ejemplar de la segunda edición del libro de Froger, aparecida en 1715. Para ese momento, la situación de Francia respecto de las posesiones españolas en América se había tornado crítica con el estallido de una nueva guerra ultramarina contra Gran Bretaña y Holanda. Cada vez más, Francia tuvo que interesarse en ella: la rama de los Habsburgo españoles se extinguía con Carlos II, y la dinastía francesa de los Borbones aspiraba a transmitir sus derechos al trono a Felipe de Anjou, nieto de Luis XIV, en contra de los parientes austríacos del rey español, aliado a Holanda, Gran Bretaña y los principados alemanes. Un conflicto a escala paneuropea enfrentó desde entonces a las monarquías borbónicas de España y Francia aliadas entre sí, contra la casi totalidad de los Estados del continente. ${ }^{19}$ La debilidad de las colonias del aliado dinástico de Francia en América atrajo la atención del Rey Sol, de sus funcionarios y de sus mercaderes, que temían con razón la expansión de intereses rivales en ese mercado colonial. La monarquía francesa despachó un agente y observador a los dominios australes españoles con la misión de informar a su gobierno sobre el estado de las defensas que amparaban las costas de Chile y de Perú: España era una aliada insegura, y una derrota en la guerra la pondría en la lista de los enemigos. El titular de esta comisión, el ingeniero militar Amedée François Frezier (1682-1773), publicó a su regreso un notable libro con catorce láminas y veintitrés mapas titulado Relación del viaje al Mar del Sur a las costas de Chile y de Perú hecho durante los años 1712, 1713 y 1714, con el detallado inventario de las características, recursos y actividades de las poblaciones coloniales españolas de la región, del que la Biblioteca del Museo Etnográfico posee un ejemplar de la segunda edición, ${ }^{20}$ dedicada al Duque de Orleáns,

18 FROGER, [François], Relation d'un Voyage de la Mer du Sud..., Op. Cit., pp. 108-113.

19 RUDE, George, Europa en el siglo XVIII. La aristocracia y el desafío burgués, Alianza, Madrid, 1982, capítulo 14.

20 FREZIER, Amedé F., Relation du Voyage de la Mer du Sud aux cotes du Chily et du Perou, fait pendant les années 1712, 1713 et 1714. Dédiée a S. A. R. le Duc d’Orleans, Régent du Royaume, par M... Ingénieur Ordinaire du Roi..., Jean-Geoffroy Nyon, París, 1716. Avec Approbation et Privilege du Roi. 
regente del reino, y publicada en 1716. Los mercaderes y armadores francesas que iban adueñándose del tráfico colonial de los españoles, cuya metrópoli se veía superada por las nuevas exigencias comerciales, organizativas y militares, se iban convirtiendo en un público lector emergente, necesitado de descripciones de las rutas al Perú, centro neurálgico del comercio español en América. Las informaciones suministradas por Frezier fueron entonces publicadas de inmediato, incluso antes de la muerte de Luis XIV, pero en la edición aparecida en 1716 -que demuestra la gran avidez por la obra-Frezier se dirige a solicitar el patronazgo del Duque, esmerándose, paradójicamente, por declarar unas menguadas intenciones para su libro dedicadas solamente, al parecer, al entretenimiento de su ilustre protector.

Es una colección de observaciones que he hecho sobre la navegación y sobre los errores de las cartas, sobre la situación de los puertos y de las radas en las que he estado. Es una descripción de los animales, de las plantas, de los frutos, de los metales y de lo que la tierra produce de raro en las más ricas colonias del mundo. Son investigaciones exactas sobre el comercio, sobre la fuerza, sobre el gobierno y las costumbres de los Españoles, los Criollos y los Naturales del país, respecto de los cuales he dicho todo con el respeto que debo a la verdad. El homenaje de todas estas particularidades que quizás podrían contribuir en alguna cosa a la perfección de las ciencias y de las bellas artes, no debe llevarse más que a los pies de Vuestra Alteza Real, que los más esclarecidos reconocen como el Padre, el Arbitro y el Protector, cualidades que no serán menos recomendables a la posteridad, que este valor heroico de haber derramado vuestra sangre, a la cabeza y con intrepidez... Me consideraré dichoso, Monseñor, si entre mis notas se halla alguna cosa que pueda distraer a Vuestra Alteza Real de las preocupaciones continuas que se toma para la felicidad del Estado... ${ }^{21}$

La labor del funcionario y del especialista se solapa aquí con la del mero cortesano, cuya tarea es servir a la recreación del soberano, incluso cuando desempeña actividades vitales para los intereses comerciales de su nación, como lo demuestra el éxito de su obra entre lectores, seguramente empresarios y burgueses. No hay invitación al público, ni promoción de otras cualidades que la que pueda proporcionar al regente el conocimiento suficiente de sus eventuales aliados o enemigos, a título casi personal.

Otro de los medios ensayados para conseguir información de ultramar fue aprovechar y traducir la de los competidores ingleses. En la Biblioteca del Museo Etnográfico de Buenos Aires se encuentran dos ediciones de los viajes de Dampier: una francesa de 1715, en cinco tomos, y otra inglesa, de 1776. Los bucaneros ingleses, convertidos en exploradores de las aguas, costas e islas americanas, eran un recurso irrenunciable, en particular William Dampier, popularizado entonces como un experto navegante del Caribe y el Pacífico españoles. La exhaustiva edición francesa de sus viajes demuestra que los franceses estaban muy al tanto de esa reputación. Publicada en Ruán por Jean-Baptiste Machuell, refleja visiblemente el indudable interés del público lector de uno de los puertos más pujantes en el comercio de

21 Ibídem, pp. 4-5. 
ultramar francés por la literatura de los bucaneros ingleses, dada la urgencia por adquirir un conocimiento los más detallado posible de rutas, puertos, climas, producciones y poblaciones de las colonias españolas, rubro deficitario en el país. El propietario inicial del privilegio real de edición, Robert Machell, miembro de una familia de libreros de Ruán -"mercader, impresor y librero", anota el privilegio real, al igual que sus parientes directos, eventuales beneficiarios del mismo- ${ }^{22}$ no se limita a publicar solamente los libros de Dampier (es decir, como se ha visto, su New Voyage round the World de 1697, los Voyages and Descriptions y el Discourse of the Winds de 1699 y, por último, las dos partes de su Voyage to New Holland de 1703 y 1709): agrega también a su edición de cinco tomos en octava los relatos de los ingleses que compartieron sus aventuras. Los tres primeros tomos incluyen los textos de Dampier de 1697 y 1699 -las dos partes del New Voyage y el Discourse-, pero al cuarto, dedicado a la primera parte del Voyage to New Holland (1703) se incorpora el relato de Wafer sobre su experiencia en Darién, y el quinto presenta la continuación del viaje a Nueva Holanda (1709) junto a la edición de Hacke de 1699. Explica el editor:

La pequeñez de este volumen (el viaje a Nueva Holanda de 1703) está tan lejos de la grosura de los otros (viajes de Dampier), que no he podido resolverme a publicarlo totalmente solo: de suerte que le he adjuntado la Relación del Señor Wafer, uno de sus compañeros de fortuna, que se ha impreso en Londres (en 1699) Está de más decir que el público se verá bien resarcido por su espera y que guardará alguna obligación conmigo por reunir a estos dos amigos. El señor Wafer nos da aquí un resumen de sus viajes desde 1677 hasta 1690, y ha descrito con mucha exactitud el Istmo de América o de Panamá, en donde permaneció varios meses... En fin, para presentar esta edición francesa más completa le he agregado, el Aviso que el Señor Halley da a todos aquellos que navegan a través de La Mancha, o Canal de Inglaterra, y que el Señor Dampier alaba mucho en la página 3 de este volumen. ${ }^{23}$

Esta intencionada selección de obras es muy cuidadosa: con un argumento semejante justifica el agregado de los viajes de Hacke a la segunda parte del Voyage to New Holland de 1709, publicada en el tomo V. ${ }^{24}$ La edición francesa de una fuente tan celebrada en Inglaterra, como la de Dampier, y la aparición de la obra de Frezier en el mismo año expresan la preocupación de sus dirigentes por apropiarse de un saber hasta entonces monopolizado por Inglaterra. Las hazañas de los bucaneros, esos pobladores marginales de las Antillas abandonadas por los españoles, cazadores de ganado, vendedores de cuero y madera, y sa-

22 En rigor, como solicitante y beneficiario del privilegio real figura Robert Machuell, quien, según se expresa en el prefacio del tomo $\mathrm{V}$ de los viajes de Dampier murió antes de la publicación del mismo. No resulta posible precisar cuál de los dos Jean Baptiste Machuell realizaron efectivamente la edición: si el Joven -probablemente hermano de Robert- o el Padre -tal vez, progenitor de ambos-.

23 DAMPIER, Guillaume, Nouveau Voyage Autour du Monde, 1698, T. IV Prefacio.

24 Ibídem, T. V, Prefacio. 
queadores de las flotas, los convertirían en modelos de súbito ascenso social, pero también de autoridad intelectual a nivel continental.

¿No intentaron los franceses, por su cuenta, repetir una experiencia semejante, arriesgada pero prometedora? Un texto francés que parece aproxima en algo al modelo de la literatura de los bucaneros es el del aventurero y mercader Dralsé de Grand Pierre, exponente de una literatura de viajes escrita por empresarios particulares de la que no abunda en la experiencia francesa de viajes que se registra en la Biblioteca del Museo Etnográfico de Buenos Aires. El joven Grand Pierre, ligado a los círculos del comercio atlántico de materias primas, esclavos y manufacturas del que Francia aspiraba a desplazar a los británicos, realizó varios viajes entre las costas de América, de África y del Caribe al calor del desarrollo de las secuelas coloniales de la Guerra de la Sucesión. Con sus experiencias publicó un instructivo librito bajo el título Relation des Divers Voyages dans l'Afrique, l'Amerique et aux Indes Occidentale, aparecido en 1718, y reimpreso en 1726 (edición del libro existente en el Museo Etnográfico) y en $1728,{ }^{25}$ lo que documenta que su contenido despertó un interés significativo. Embarcado en ese primer viaje en 1707, Grand Pierre llegó Buenos Aires en el navío La Esfera y conoció más tarde las costas de África, en las cuales el navío en que viajaba se proveía de esclavos. Este tipo de trayectos se repitió más tarde, incluyendo visitas a Benín, Martinica y México. En su dedicatoria al Conde de Tolosa, Almirante del Reino, Grand Pierre justifica la importancia de su obra:

Tantas obras de esta naturaleza han aparecido en Público, que temería que la mía no pudiese llegar hasta Vos, MONSEÑOR, si la bondad de Vuestra Alteza Serenísima no abriera los ojos. Recomendable, en principio, es convencerse de que atrae todos los corazones. Deja el campo libre a aquellos que tienen la felicidad de acercársele.

La obra de Grand Pierre - pequeña, divertida y fácil de leer-se dirigía a un público vasto y curioso - "aquellos que tienen la felicidad de acercársele"- y aspira a llenar ese hueco de autores que escriben al impulso de una experiencia que no es la del funcionario real: de ello resulta una notable guía social y cultural de los "estilos de vida" de las tierras de ultramar que visitó y de las cosas que valía la pena saber para obtener ventajosas transacciones en ellas. La dinámica social francesa que impulsaba la expansión ultramarina parecía no promover fácilmente el surgimiento de aventureros individuales de la talla de los ingleses. Sus narraciones más renombradas y exhaustivas proceden de agentes estatales, como la de Amedé Frezier. Cada vez más necesitados de impulsar el aumento de ese público lector

25 GRAND-PIERRE, Dralsé, Relation de Divers Voyages dans l'Afrique, l'Amérique et aux Indes Occidentales. Avec la description du Royaume de Juda, et quelques particularitéz touchant la vie du Roi régnant. La relation d'une île nouvellement habité dans le Détroit de Malaca en Asi, et l'Histoire du deux Princes de Golconde, 1726, pp. 2-3. Sobre el viaje de Dralsé de Grand-Pierre al Plata, ver también RIPODAS ARDANAZ, Daisy (editora), Viajeros al Río de la Plata 1701-1725, Academia Nacional de la Historia, Buenos Aires, 2002, pp. 13-76. 
burgués que leyera literatura de viajes -que, sin embargo, parecía ampliarse a través del éxito editorial de obras como las del propio Frezier y de Dralsé, interesado tal vez en el abastecimiento de unas colonias españolas necesitadas del comercio francés tras la caída del monopolio sevillano ${ }^{26}$ editores y funcionarios se complementaban de la manera más eficaz posible, pero tropezaban con un sistema de relaciones políticas, sociales y culturales que, en general, enfriaba ese entusiasmo. El lector curioso, inclinado a ver en el libro de viaje una mercancía exótica y prestigiosa antes que un objeto de consumo útil -más apropiado para el noble o el burgués rentista que para el empresario o armador-parece prevalecer como el medio adecuado con el cual el editor, aunque más interesado en convertir en mercancía un saber práctico, procura seducir a un público inicialmente más distante, allegándole a través de la experiencia vital que se narra un instrumento eficaz para aplicarse a las nuevas rutas, puertos y tráficos con las colonias americanas, que aunque Dampier y sus amigos conocían tan bien, parecían tal vez menos interesante para una burguesía ruanesa que, sin embargo, debía aprovecharse urgentemente de la coyuntura.

\section{Circunnavegaciones, expansión inglesa y crisis francesa (1740-1774)}

La contraposición entre sociedades, empresa colonial y narraciones de viaje alcanzaría su momento culminante en torno a las dos grandes guerras que impusieron el predominio colonial británico sobre el francés: la Guerra de la Sucesión Austríaca (1740-1748) y la de los Siete Años (1756-1763). ${ }^{27}$ La derrota francesa - primero aliada con Prusia, luego con Austria, pero siempre enemiga de Gran Bretaña- tuvo por escenario no solamente los campos de batalla de Europa, sino también los de ultramar. Durante la guerra de la Sucesión Austríaca, la descollante expedición del almirante inglés George Anson contra españoles y franceses en las colonias americanas (1740-1744) concitó la admiración de los contemporáneos tanto por sus resultados militares como marítimos, dado que completó una nueva circunnavegación, y la aparición de su crónica de viaje -que redactó el capellán de la expedición Richard Walter- publicada por primera vez en 1748 (edición que se encuentra en el Museo Etnográfico) le abrió camino a un renombre que se completaría su promoción al grado de Lord. El capellán Walter dedicó el resultado de su trabajo al Conde Beckford, secretario de Estado del rey Jorge II (1727-1760). La dedicatoria es, al mismo tiempo, una apología de la armada británica y de su empresa de expansión ultramarina, tanto a través de la guerra como del comercio.

26 MOUTOUKIAS, Zacarías, Contrabando y control colonial en el siglo XVIII, CEAL, Buenos Aires, 1988; VILLALOBOS, Sergio, Comercio y contrabando en el Río de la Plata y Chile (1700-1811), Eudeba, Buenos Aires, 1967.

27 RUDE, George, Europa en el siglo XVIII. La aristocracia..., Op. Cit., capítulos 13-14; DIAZ, Furio, Europa: de la Ilustración a la Revolución, Alianza Editorial, Madrid, 1994, capítulo 7. 
La siguiente narración es un éxito muy singular que se dirige a Vuestra Gracia, tanto en retribución de infinitas obligaciones que el Comandante en Jefe os ha profesado en todo tiempo por recibir vuestra amistad, como así también porque su tema reclama naturalmente y por sí mismo el patronazgo de alguien bajo cuya dirección, la Armada Británica ha retomado su antiguo espíritu y lustre, y lo ha exaltado al extremo por sus victorias, las más decisivas, y (si se considerase la lucha y el número de las capturas) las más importantes que puedan hallarse en sus Anales. Por cierto, una serie ininterrumpida de éxitos, y una manifiesta superioridad, que triunfaron sobre el enemigo tanto en el comercio como en la gloria, parecen ser necesario efecto de un renacimiento de la estricta disciplina y una imparcial consideración de sus méritos y servicios. Hay registros que deben distinguir el feliz período del tiempo en el cual Su Gracia presidió y asistió a la más adecuada cuestión de la historia, con una distinción propia de su naturaleza.... Que los eminentes talentos, magnanimidad y celo desinteresado, de los cuales el público ya ha cosechado tan señalados beneficios, pueda igualmente en todo tiempo proporcionar los mismos éxitos en el avance hacia la prosperidad de Gran Bretaña, es el ardiente deseo de My Lord. ${ }^{28}$

Es notable que a continuación de esta exaltada defensa de las glorias navales británicas logradas por la expedición del flamante Lord Anson, figure también la extensa lista de apellidos -entre los que destacan algunos de la más rancia aristocracia- de los suscriptores de la edición, en una expresión muy nítida de la vinculación entre las hazañas guerreras, los objetivos políticos y la ventajas empresariales -"señalados beneficios cosechados por el público", escribe Walter- que la clase dirigente inglesa procuraba obtener de las acciones bélicas y marítimas de sus agentes.

Es notable, asimismo, el contraste entre los propósitos que permite descubrir esta primera edición inglesa del viaje de Anson, y los de la traducción francesa que se encuentra en el Museo Etnográfico de Buenos Aires, publicada en Amsterdam y Leipzig en 1749. La portada reproduce el contenido de la original inglesa (Voyage autour du monde fait dans les annés MDCCXL, I, II, III y IV Par George Anson, presentement Lord Anson, Commandant en chef d'une escadre envoyée par Sa Majesté Britannique dans la Mer du Sud, tiré des journeaux et autres papiers de ce Seigneur et publié par Richard Walter... traduit de l'anglois) y lo mismo debe decirse de su introducción, que realiza una exhaustiva crónica de los viajes al Mar del Sur desde el descubrimiento del Estrecho de Magallanes. Sin embargo, la dedicatoria al Conde de Gantz que firman los editores, Arkstee et Markus, expresa valores y prácticas señoriales mucho más arcaicas que las inglesas, destacadas solamente, una vez

28 ANSON, George, A Voyage round the World in the Years MDCCXL, I, II, III y IV by... Esq., Commander in Chief of a Squadron of His Majesty's Ships, send upon an Expedition to the South Sea, compilated from Papers and others Materials of the Right Honorable Lord George Anson, and published under his Direction by Richard Walter, M. A, Chaplain of His Majesty Ship The Centurio, Printed for the Author By John and Paul Knapton in Ludgate Street, London, 1748, pp. 2-3. 
más, por la exaltación del coraje personal y la gloria militar del Almirante equiparado al de su noble destinatario:

El viaje, que nos tomamos la libertad de dedicaros, es quizás uno de los más interesantes que haya aparecido jamás: al menos, nos atrevemos a decir que no conocemos ninguno como este que, en cualquier caso, pueda resultarle preferible, Costas desconocidas descritas con exactitud, observaciones propias para perfeccionar la Geografía y su Navegación, accidentes imprevistos de un tipo que la licencia de sí mismo haría incluso difícil de imaginar, acontecimientos importantes cuyo éxito se debió, principalmente al jefe de la expedición, pero por sobre todo el resto, al carácter humano, firme y generoso de este jefe, son objetos que os complacerán tanto más cuanto que conocéis de grandes hombres en grandes acciones, Este es uno de los frutos, Monseñor, que el profundo conocimiento de la historia os ha procurado, y por lo que a nosotros nos interesa, hemos creído un deber ofreceros esta relación de trabajos de Milord Anson, en la cual vos, de entre un pequeño número, extraeréis mil casos que escaparán a los lectores ordinarios. ${ }^{29}$

Dos ediciones a ambos lados del Canal de la Mancha, con dos públicos distintos en sus prácticas y objetivos, a pesar de compartir un mismo origen aristocrático, y dos formas de editarlas y dedicarlas a cada uno de ellos.

En 1756, cuando se iniciaba la Guerra de los Siete Años aparece en Lyon una nueva edición francesa del viaje de Anson, a la que se agregó un Suplemento que puede encontrarse en el Mueso Etnográfico de Buenos Aires, y que narraba las peripecias de los náufragos de The Wager, uno de los navíos de su expedición, que zozobró en el pasaje entre el Atlántico y el Pacífico. Aunque, como se ha visto, desde el comienzo del siglo XVIII, el interés de los franceses por el Atlántico Sur y la ruta magallánica se acrecentaba sin cesar, y circulaban ya ediciones francesas de la hazaña de Anson, esta última se detenía con primor en la presentación de una memoria re-escrita por el editor a partir de los testimonios directos sobre las forzadas exploraciones de los náufragos de The Wager por las rutas de la Patagonia austral y de Chile. Es notable, sin embargo, de qué manera un texto tan estratégico -que se publica, detalla el editor lionés, para dar a conocer las ventajas de un territorio “... tan fértil en pasturas, tan abundante en caballos, en ganados de toda especie; un país abundante y regado para el cultivo .... y que “... ofrece ventajas ciertas... minas y peleterías... [que] no debe ser puesto en el rango de tierras que se pueden abandonar sin consecuencias"- se sigue armonizando, a cualquier precio, con la adecuada satisfacción del buen gusto de los lectores, que se interpone entre estos y una presentación "realista" de los datos aportados

Parece que hubiera debido contentarme con traducir estas memorias (de los náufragos) y darlas al Público tal como y como son. Pero, además de que estos hubiera sido

29 Voyage autour du Monde fait dans les années MDCCXL, I, II, III y IV par George ANSON, présentement Lord Anson... p. 1. 
remitir muchas veces los ojos del lector a las mismas cosas repetidas en términos diferentes, estas memorias se encuentran escritas con tan poco orden de corrección, que no habría medio de presentarlas, dejándolas con tal descuido groseras y desagradables. Sus autores, buenos hombres de mar, y en absoluto hombres de letras, han usado de este estilo brutal y descomedido, ordinario en todos aquellos que no tienen la costumbre de escribir...

He aquí el caos que una traducción literal me ofrecía a desenmarañar. Fue necesario rebuscar en esta ruina, seleccionar en la mezcolanza, separar lo bueno de lo malo... He trabajado, en una palabra, en reunir la precisión con la exactitud y en conservar el fondo de las cosas, en darle una forma que no fuese demasiado redundante. Ese trabajo no ha sido mediocre: feliz si tomando sobre mí todo lo que había de aburrido $\mathrm{y}$ de disgusto, no parece de este modo para los lectores. ${ }^{30}$

Una vez concluida la guerra, vencida Francia, frustrados sus planes de expansión y perdidos sus territorios coloniales en América del Norte y en la India, el intento de exaltar su reivindicación como gran potencia naval y colonial asumirá la forma de una proeza que la marina francesa se debía desde el siglo XVI: el monarca comisionó entonces a Louis Antoine de Bougainville para "devolver" las Islas Malvinas -que él mismo había poblado con colonos de su país- a la corona española y, a continuación, para completar la ruta de lo que se convertiría en una tardía primera circunnavegación francesa. El auspicio oficial y la primacía ilustrada de las letras de Francia sobre el resto del Continente otorgarían a la empresa de Bougainville una repercusión internacional cuya causa quería atribuirse a la singularidad de sus observaciones e informes antes que a la ejecución, efectuada ya tantas veces durante siglos por españoles, ingleses y holandeses, del viaje alrededor del mundo. La elevación a la consideración real de la obra resultante de la expedición, el Viaje alrededor del mundo por la Fragata de S. M. La Bordeuse y la urca L'Etoile asume así todas esas deudas y se presenta como fruto de la fidelidad y del servicio al soberano y al público lector, identificado con la Humanidad:

El viaje del que voy a rendir cuenta, es el primero de esta especie emprendido por los Franceses y ejecutado por los navíos de Vuestra Majestad. El mundo entero le debe ya el conocimiento de la figura de la Tierra. Aquellos de Vuestros súbditos a los cuales se ha confiado este importante descubrimiento, elegidos entre los más ilustres sabios de Francia, han determinado las dimensiones de la Tierra

La América, es verdad, descubierta y conquistada, la ruta por mar abierta a las Indias y a las Molucas, son prodigios de coraje y de éxito que pertenecen sin contraste a los Españoles y a los Portugueses... Alentados por su ejemplo, navegantes ingleses y holandeses encontraron nuevas tierras, y enriquecieron a Europa mientras la ilustraban.

30 Voyage a la Mer du Sud fait par Quelques Officiers Commandants le Vaisseaux Le Wager pour servir de suite de Voyage de George Anson. Traduit de l'Anglais. A Lyon, Chez Les Frères Duplain, Libraires, Grand rue Mercerie, 1756. Avec Approbation et Privilege du Roi, pp. 7-9. 
Pero esta especie de primacía y de primogenitura en materia de descubrimientos, no impidió a los Navegantes franceses revindicar con justicia una parte de la gloria ligada a estas brillantes pero penosas empresas. Muchas regiones de América han sido descubiertas por súbditos valerosos de los Reyes. Vuestros Ancestros... Diferentes causas, tanto interiores como exteriores han parecido suspender, desde entonces, en esta perspectiva, el gusto y la actividad de la nación.

Vuestra Majestad ha querido beneficiar los descansos de la paz para procurar a la Geografía de conocimientos útiles para la Humanidad. Bajo Vuestros auspicios, Señor, hemos entrado en la carrera, las pruebas de todo género nos salen al encuentro a cada paso, la paciencia y el celo que nos han faltado. Esta es la historia de nuestros esfuerzos, que me atrevo a presentar a Vuestra Majestad, Vuestra aprobación proporcionará el éxito. ${ }^{31}$

El proclamado logro naval y editorial de Bougainville atravesó rápidamente el Canal de la Mancha, y casi de inmediato se imprimió la traducción al inglés del último viaje de circunnavegación. Su editor, el pastor naturalista y viajero John Reinhold Forster (17291798), que acompañaría a James Cook en su expedición al Pacífico de 1772-1775, se mostró mucho más críticamente consciente de los verdaderos logros y límites del relato francés y explicitó en términos bastantes directos la inferioridad francesa frente a los británicos, tanto en términos científicos y geográficos como políticos. Tras encomendar la obra al beneplácito de James West, presidente por entonces de la Royal Society de Londres, anota prolijamente sobre la obra de Bougainville:

Las noticias y observaciones náuticas son siempre interesantes, de cualquier parte que ocurra que ellas provengan, cuando se prueban expresión de reconocidas habilidades; y nadie, pienso, cuestionará en ello a Mister de Bougainville.

La superioridad de los descubrimientos británicos en el gran océano, entre América y Asia, no puede ser confirmada más que por un auténtico relato de los descubrimientos de la nación rival que, después de gran esfuerzo, y con la ventaja de haber reemplazado a los españoles con todo lo necesario respecto de la grandes distancias al lugar de origen, que si bien se adentraron antes en el Océano Pacífico del Sur, descubrieron sin embargo muy poco; y lo que descubrieron, ha sido en parte visto por los navegantes ingleses, o al menos los de las épocas más antiguas; por lo cual el honor de los descubrimientos más grandes hechos en los últimos dos siglos, en aquellos remotos mares, está reservado a la nación británica, y a su espíritu y perseverancia en conducir este grande e interesante evento...

Y entonces, luego de acotar los méritos navales de la expedición, Reinhold se lanza con

31 BOUGAINVILLE, Louis A., Voyage autour du Monde par la Fragate du Roi la Bourdeuse et la Flûte L'Etoile en 1766, 1767, 1768 et 1769. A Paris, Chez Saillant e Nyon, Libraires, rue S, Jeande-Beauvais De l'Imprimerie de Le Breton, premier Imprimeur du Roi, 1771. Avec Approbation et Privilege du Roi, pp. 1-2. 
notable perspicacia, digna de un científico, sobre los estilos literarios y editoriales de los adversarios, sus logros y sus carencias en comparación con los que caracterizan las de los británicos, que también en esto se demuestra su superior:

El Francés, que es tan notable para la impresión con la que ornamenta sus principales publicaciones, encontrará que las cartas adjuntas a esta traducción, aunque reducidas a la sexta parte de su superficie original; son, sin embargo, infinitamente superiores en lo que hace a nitidez, conveniencia y cuidado. Sin ser menos útil, hemos reunido en nuestras cartas la información la totalidad de los trayectos de sus navíos, desde el comienzo de su descubrimiento hasta Batavia. La carta del Estrecho de Magallanes es del mismo tamaño, y de la misma escala que el original, pero más detallada; y los nombres por los cuales los ingleses llaman a diversos puertos del continente, las bahías y las arribadas, se han agregado en su totalidad a los nombres franceses...

Por último, el reverendo Forster se dedica a poner en un adecuado contexto los meritos del comandante francés como observador y científico:

Aunque Mister Bougainville es un hombre de indudable veracidad y capacidad, ha sido, sin embargo, en algunas instancias, engañado por falsos informes, o parcialidad a favor de su nación: en algunas notas adicionales hemos corregido, en la medida que podíamos, estos errores, revindicando parcialmente a la nación británica, respecto de lo cual pensamos que el autor se ha sido; porque el amor del propio país es, en nuestra opinión, muy consistente con la justicia y la buena educación, cualidades que nunca se necesitarían para un filósofo... (VI-VIII). ${ }^{32}$

Los lectores de Forster -incluidos los de la Royal Society- son conscientes de que el viaje francés es una obra de interés para "toda compañía" -escribe el editor-interesada en la empresa de la circunnavegación y digna de figurar entre aquellas que necesita conocer un público inglés de marinos y comerciantes, menos atraídos por el "ornamento" que los franceses dan a sus relatos de viajes. Sin embargo, el contraste entre los resultados de las exploraciones inglesas y las francesas, y sus efectos concretos, en términos militares y económicos, demostrados durante las guerras del siglo XVIII, no puede ocultar lo que se sabe a ambos lados del Canal de la Mancha: que la hazaña de Bougainville ha nacido opacada por la posición subordinada de la potencia marítima francesa a la británica. Y mientras los franceses se aprestaban a navegar el Pacífico por primera vez, el comodoro inglés John Byron -joven oficial náufrago del navío The Wager, de la flota de Anson- al mando del Dolphin, completaba la sexta circunnavegación inglesa en un record de tiempo no alcanzado hasta entonces (1764-1766). En la edición disponible en el Museo Etnográfico (Londres, 1767),

32 Voyage round the World Performed by Order of His Most Christian Majesty In the Years 1766, 1767, 1768 and 1769 by Lewis de Bougainville Colonel of Foot and Commodore of the Expedition in the Frigate La Bourdeuse and the Store-ship L'Etoile Translated from the French by John Rinhold Forster... London, 1772. 
que también dispone de una traducción francesa casi simultánea, precedida de un estudio sobre la existencia de los "gigantes patagónicos" (París, 1767), ${ }^{33}$ el autor anónimo, marino del Dolphin, solicita benevolencia para sus méritos literarios, pero encarece la objetividad de su testimonio:

El autor de este Viaje se da cuenta de que ni sus conocimientos ni sus habilidades lo harán digno de figurar en el Mundo de las Letras. No está acostumbrado a escribir, ni tiene ninguna inclinación que lo distinga en ese sentido; estando preparado para una profesión que requiere otro tipo de argumentos o implementos que los se usan en la Imprenta. Después de esta declaración, tiene la esperanza de poder reclamar la indulgencia del Lector, si la hallase, porque esta Obra se encuentra despojada de esas elegancias y decoraciones de estilo, que en esta época en que el Gusto y el Discernimiento literario son tan entusiastamente requeridas; sus propósitos, sostiene, fue representar la verdad y presentarla con cierto atuendo, como consistente con su natural simplicidad, y aún ni siquiera esto hubiera conseguido sino para la grata curiosidad, y para remover la dudas de sus compatriotas concernientes a algunas materias que han ocasionado últimamente muchos altercados. El curso de la Obra, sin embargo, ha sido tan conciso como le ha sido posible, y omitió tantas circunstancias del viaje y de la conducta de su tripulación, como que no siendo de interés, no podrían haber respondido a ningún otro propósito que el de aumentar el tamaño y el precio del volumen. ${ }^{34}$

La sustancia de la información sobre las calidades del estilo, la invocación a un público lector más bien general y anónimo que particular y conspicuo, la conversión gradual del libro en una mercancía a la que se accede en el mercado parecieron ir imponiéndose en las apelaciones a los lectores ingleses antes que en las de los franceses. El antecedente de la literatura de bucaneros, surgida en buena medida al margen de cualquier patrocinio oficial o nobiliario, parece ser un antecedente decisivo, transformador, frente a un editor y lector francés, todavía - de grado o por fuerza- más interesados en los logros estilísticos y en las "curiosidades" aportada por la literatura de viajes.

\section{Conclusión: Revolución, esperanzas y utopías}

Como lo demuestran la edición inglesa del viaje de Bougainville y la francesa del de Byron (prácticamente simultáneas con las originales), a pesar de que a lo largo de la década de 1740, la competencia anglo francesa en Europa y ultramar quedó resuelta a favor de Gran

33 Voyage autour du Monde fait in 1764 et 1765 Sur le Vaisseaux de Guerre Anglais Le Dauphin, commandé par Le Chef d'Escadre BYRON dans le on trouve une Description exacte du Détroit de Magellan, et les Géants appelés Patagons, A París, 1747.

34 A Voyage round the World in His Majesty's Ship The Dolphin. Commanded by the Honourable Commodore BYRON in which is Contained a faithful Account of the Several Places, People, Plants, Animals, etc. See on the Voyage... The Second Edition, London, 1747, p. 1. 
Bretaña y en contra de Francia, la aguda y recíproca vigilancia editorial sobre los logros del rival no decaería y su vigencia seguiría presente en la ediciones de viajes a ambos lados del Canal de la Mancha, por lo menos hasta la Revolución Francesa, y aún después, cuando el dominio sobre el mundo ultramarino pasase a convertirse en una empresa ya compartida y dividida con toda Europa. Pero hacia finales de la década de 1770, los viajes de James Cook (1728-1779) habían agotado prácticamente los espacios ultramarinos explorables, dejándolos limitados, solamente -salvo en algunos puntos todavía de interés, como los estrechos interoceánicos del Nordeste y del Noroeste- al círculo polar antártico.

La consagración de Cook como el mayor explorador del siglo, de sus viajes, no sólo representó el triunfo geopolítico y económico de Gran Bretaña como primera potencia naval y comercial; involucró también un nuevo concepto de la superioridad británica en términos geográficos y científicos. Una extraordinaria edición de los viajes de Cook se encuentra en la Biblioteca del Museo Etnográfico, que bien puede considerarse una especie de enciclopedia general sobre los descubrimientos en el Océano Pacíico a lo largo del siglo XVIII, bajo el título A Journal of a Voyage to the South Sea on His Majesty's Ship The Endeavour Faith fully Translated From the Papers of the Late Sidney Parkinson Draughtsman to Sir Joseph Banks, Bart. In his Expedition with Dr. Solander round the World... And An Appendix Containing an Account of the Voyages of Commodore Byron, Captain Wallis, Captain Chartered, Monsieur Bougainville, Captain Cook, and Captain Clerke (Londres, 1784) editado sobre la base de las notas científicas y astronómica de los naturalistas Joseph Banks (1743-1820) y Daniel Solander (1773-1782), quienes habían viajado junto a Cook en su navío con el propósito de realizar sus investigaciones en los Mares del Sur.

El estallido de la Revolución en Francia, la destrucción del absolutismo -a cuya incapacidad organizativa y militar le atribuyen algunos autores el fracaso de la empresa colonial y su consecuente descrédito entre la burguesía ${ }^{35}$ y los cada vez más resonantes éxitos militares y políticos de la flamante república revolucionaria en el Continente, reavivaron destellos de una esperanza renovada para la empresa ultramarina francesa y su literatura. Un testimonio de ello aparece una edición del viaje de Bougainville publicada en 1793 -durante los momentos más críticos del período revolucionario francés, en el que los dirigentes jacobinos se proponían volver a fundar, desde sus cimientos, el orden político e institucional de Francia- a la cual se anexa, en su tomo tercero, el Journal d'un voyage autour du monde fait par M: M. Banks et Solander, Angloises, en 1768, 1769, 1770 y 1771, traduit de l'anglois par M. de Freville, es decir, una traducción francesa de un digesto de la obra de Bamks y Solander. El objetivo radical de los editores, en plena consonancia con las expectativas de una república francesa pujante, parece ponerse de manifiesto en esta iniciativa francesa de reiniciar el duelo editorial con los británicos.

35 Ver particularmente SKOCPOL, Theda, Los Estados y las revoluciones sociales. Un análisis comparado de Francia, Rusia y China, Fondo de Cultura Económica, México, 1984. 
M. de la Lande publicó, en 1764, una Memoria sobre el pasaje de Venus, que debió ocurrir el 3 de junio de 1769, en el cual demostró que el sitio más apropiado para esta observación se encontraba en medio del Océano Pacífico. La Sociedad Real de Londres solicitó al gobierno un navío para ir a observar este fenómeno interesante. El gobierno inglés, al que este proyecto le pareció no menos ventajoso para el comercio, que sirve al progreso de las ciencias, mandó a armar un navío al capitán Cook, y en el cual se embarcaron M. M. Banks y Solander, sabios que gozan en toda Europa de una reputación justamente merecida. ${ }^{36}$

Luego de presentar en estos términos escuetos y bastante apresurados los alcances y el interés de las memorias cuyo resumen se publica a favor de la difusión del conocimiento científico, irrumpen una vez más, en las palabras del editor los grandiosos bosquejos de una plan de colonización proyectada sobre supuestos territorios aún no descubiertos, con un énfasis y una extensión que quizás no se leía desde la Guerra de la Sucesión Española.

Una expedición no menos brillante (que la de James Cook) y que cubrirá de gloria inmortal al Experimentado Capitán al que le sea confiada es la de abrirse una ruta en el Mar del Sur por el Mar Glacial. M. de Boynes, que no duda del éxito de esta navegación, obra para Francia de nuevas fuentes de felicidad, de poder y de riqueza, ha prometido a la Academia de Ciencias hacer el intento, en la próxima primavera, de este pasaje tan ardientemente deseado en Europa entera desde hace dos siglos.

Es a propósito de este intento proyectado que se ha agregado a continuación de este Diario, una Carta, en la cual se expone el sistema de M. Ángel (sobre el hallazgo de un paso en el Noroeste) Las luces y reflexiones de este sabio geógrafo sobre las posibilidades de este pasaje, los métodos para ejecutarlo, y las grandes ventajas que proporcionaría, no pueden dejar de satisfacer al público.

A la expectativa de los pasos boreales nunca descubiertos entre el Atlántico y el Pacífico, se suman otras nuevas esperanzas, que recrean, imaginarios paralelos con los hallazgos portugueses y españoles en las costas de América y Asia.

Se sabe bastante sobre que ya no hay dudas respecto a verificar la existencia del estrecho del Norte, sino solamente en relación a cómo reconocerlo bien, a fin de poder situar allí los depósitos sobre las costas de América y en alguna de las islas que se encuentran al Este, desde el momento en que se puedan formar los establecimientos más útiles al Oeste y al Nordeste de California. Las relaciones de los Españoles y de Drake nos enseñan que estas bellas regiones, regadas por grandes ríos, ofrecen todo lo que puede hacer florecer a las colonias. Ah! qué situación más ventajosas para un inmenso comercio!

36 Voyage de M. de Bougainville contenant le Journal d'un Voyage autour du Monde fait par M.M. Banks et Solander, Anglaises, en 1768, 1769, 1770 y 1771. Traduit de l'Anglais par M. de Freville Tome Troisième. A Paris. Chez Gay et Gidet Libraries, rue d'Enfer No 721, 1793, pp. 3-4. 
Si se desea poner en duda los relatos de M. M. Jeremie y de la Hontan, que nos aseguran que se encontrarían al Norte en el continente de América los pueblos civilizados que conceden al oro y a la plata los usos que nosotros damos al hierro y al cobre, es necesario al menos convenir que la mar meridional presenta en todas partes riquezas invalorables. Hacia el sur están las Islas Salomón, a las cuales e ha dado ese nombre a causa de sus ricas producciones; la tierra austral de Santa Espíritu, descubierta por Quirós; hacia el Este tiene a México y a Perú; hacia el Oeste a Japón. México, Filipinas, las Molucas, Nueva Guinea... todos países ricos y abundantes. ${ }^{37}$

Y el discurso asertórico sobre la posibilidades de expansión vienen a rematarse con la seguridad de que se encuentran al alcance de la mano de Francia:

Es incontestable que el establecimiento en las regiones que se extienden en los climas fríos en las que se encuentran las producciones más preciosas de la naturaleza, deben hacer esperar los descubrimientos más grandes y más singulares para el espíritu humano, y procurar, en vistas al comercio, las mismas ventajas que los Españoles han encontrado en México y en Perú, los Portugueses en Brasil y los Holandeses en Batavia. $^{38}$

Detrás de su pretensión de difundir contenidos científicos, la traducción en Francia del diario de los naturalistas que acompañaron a Cook, el campeón de la empresa ultramarina británica, despunta la utopía geográfica que reivindica la grandeza futura de una empresa nacional que impulsará la república jacobina, continuadora tenaz, en este campo, de la obra de la monarquía absolutista depuesta. Un nuevo El Dorado parece renacer como esperanza cerca de las costas de Alaska, Canadá y, tal vez, Siberia. Junto a Inglaterra, también Francia -una de "las dos naciones más esclarecidas de Europa"- escribe el editor, consolidará al fin un vigoroso dominio colonial y pagará su deuda con la Humanidad en cuanto a los avances geográficos y científicos y a la acumulación de riquezas y poder.

Con el final revolucionario del siglo XVIII volvía a sus orígenes la tradición francesa de los viajes y de la literatura que le servía como legitimación y propagación. Los tópicos del período de la monarquía absoluta renacen tras la crisis política del Antiguo Régimen, pero también del hundimiento de su empresa colonial liquidada durante la Guerra de los Siete Años. La retórica literaria que explotaba el gusto de un público curioso y ávido de rarezas y una exaltación de la empresa colonial como misión superior de la monarquía en alianza con sus nobles y sus hombres de fortuna parecieron ser rasgos compartidos por la literatura de viajes a ambos lados del Canal de la Mancha. Sin embargo, a través del estudio de las ediciones existentes en el Museo Etnográfico, se tiene la nítida impresión de que un público más atraído por las proezas militares o las especulaciones filosóficas predominaba menos

37 Voyage de M. de Bougainville..., Op. Cit., pp. 9-10.

38 Ibídem, pp. 11-13. 
entre los lectores ingleses que entre los franceses, en los que los nobles y funcionarios de Estado, los literatos académicos y los burgueses ennoblecidos parecieron formar mayoría.

Los aportes de Robert Darnton y Roger Chartier ${ }^{39}$ han demostrado como la práctica social de la lectura de textos impresos, lejos de resultar apenas un medio para el diagnóstico sobre la circulación social de ideas y conocimientos, es un instrumento clave para abordar valores, expectativas y "representaciones" - concepto básico en la obra de Chartier-de los públicos lectores entre los que circulaban los libros, y que incluso hasta su materialidad concreta da cuenta del empleo que han pensado para ellos los editores, o de la aceptación lograda por parte del público. En tal sentido, es posible preguntarse en qué medida nos informan los libros de viaje del Museo Etnográfico sobre sus editores, sus públicos y sus usos en Francia e Inglaterra de los siglos XVII y XVIII. En principio, las prácticas escriturarias de ambas literaturas emergían de tendencias presentes en ambas sociedades, y expresaban los rasgos predominantes de sus proyectos de expansión colonial. En el período de su monarquía absoluta, Francia trataba de mostrar que los territorios conquistados constituían, además de una expansión comercial y territorial, una ratificación visible del carácter universal de su monarquía y su religión, impulsada por agentes fieles a su rey; ${ }^{40}$ a la caída de éste, el modelo utópico revolucionario se trasladó a ultramar para encontrar allí los medios para impulsar una felicidad que consideraba su meta dentro del nuevo orden republicano. Esta inamovible vinculación entre expansión ultramarina y patronazgo estatal proveyó a Francia de notorios intelectuales y funcionarios entre los informantes y propulsores de su empresa de expansión, pero careció mayormente de un agente social que sí desempeñó un importante papel en la difusión de la literatura de viajes: en Inglaterra, y aunque más poderosa en territorio y población que su rival, permaneció también más imbuida por tradiciones nobiliarias y cortesanas que siguieron viendo en la expansión ultramarina y en su difusión el privilegio de una clase guerrera, instruida y minoritaria, y destinada a proveerla, también ella, de ocasiones de gloria y prestigio, informaciones curiosas y raros relatos editados para su solaz, con la mayor pulcritud y elegancia posibles.

En Inglaterra, en cambio, la mayor pluralidad de actores sociales y culturales involucrados en la literatura de viajes inglesa -como los surgidos de la flamante Royal Society y,

39 Ver particularmente para CHARTIER, Roger, El orden de los libros. Lectores, autores, bibliotecas en Europa entre los siglos XIV y XVIII, Gedisa, Barcelona, 1994; también del mismo autor, Espacio público, crítica y desacralización. Los orígenes culturales de la Revolución Francesa, Gedisa, Barcelona, 1995; y para DARNTON, Robert, Edición y subversión. Literatura clandestina en el Antiguo Régimen, Fondo de Cultura Económica, México, 2003; también del mismo autor, El coloquio de los lectores. Ensayos sobre autores, manuscritos, editores y lectores, Fondo de Cultura Económica, México, 2003.

40 Ver particularmente BURKE, Peter, La fabricación de Luis XIV, Nerea, Barcelona, 1995; también MONOD, Paul Kleber, El poder de los reyes. Monarquía y religión en Europa 1589-1715, Alianza Editorial, Madrid, 2001. 
los bucaneros originados de la dinámica social del Caribe y Centroamérica y, por supuesto, en su propia empresa colonial- le proporcionaron mayores oportunidades de librarse de la herencia monárquica y señorial dentro de la cual había surgido y dado sus primeros pasos, al igual que la de Francia. Esa incipiente diferenciación en discursos y prácticas coloniales quizás contribuya a comprender no solo parte de la superioridad marítima inglesa -explicable, a su vez, por múltiples razones- sino también su mayor capacidad para legitimarse socialmente, consolidar su desarrollo, encontrar un público más allá de las esferas oficiales y de la nobleza, y movilizar así más recursos que aquellos de los que disponía su rival, superiores en conjunto. En tal sentido, la literatura de viajes inglesa pareció contar con avales sociales más amplios y estables, que le confirieron mecanismos de publicidad y participación mucho más dinámicos para obtener de su propagación nuevas fuentes de hombres y recursos para su desarrollo.

Después de 1740, los editores ingleses pudieron hacer coincidir plenamente la situación de objetiva superioridad británica en los mares con el amor a la propia patria, aunque ese nacionalismo militante no los obligara, en ningún modo, a renegar de la posibilidad de emplear los conocimientos adquiridos por el adversario en provecho propio. Esa vitalidad en el mercado de libros se mostró siempre sensible a las demandas de su público, y explica el hecho de que la competencia bélica anglo-francesa, reiniciada tras la guerra de Independencia de las Trece Colonias (1774-1783), le permitiera volver a editar, junto con muchas otras, incluso la obra ya ampliamente superada de William Dampier: la Biblioteca del Museo Etnográfico cuenta con una sobria edición londinense, de 1776, de un libro aparecido por primer vez casi ochenta años antes. ${ }^{41}$

En el caso de Inglaterra, la carrera por el dominio de los mares se desarrolló a partir de dos formas diversas: si bien las obras de Anson y Byron expresaban los objetivos de una armada británica al servicio de los intereses de su aristocrática clase gobernante, hombres como Dampier, Waffer o Sharp escalaron posiciones públicas gracias a la valiosa información que aportaron por su propia cuenta. En Francia, en cambio, los agentes del Estado monárquico como Frezier y Bougainville, o los fieles servidores intelectuales de su nobleza, como Renneville y De Brosses, -que en algunos casos jamás se embarcaron- restaron lugar a aventureros individuales como Grand Pierre, cuya obra, sin embargo, parece haber gozado de gran popularidad.

Recibido: 05/10/2011

Aceptado: 21/11/2011

41 Voyages and Adventures of Capt. WILLIAM DAMPIER Wherein are described The Inhabitants, Manners, Customs, Trade, Harbours, Soil, Animals, Vegetables etc. of the Principals Countries, Islands etc. of Asia, Africa and America..., London, 1776. 